\title{
Decreased human antigen $R$ expression confers resistance to tyrosine kinase inhibitors in epidermal growth factor receptor-mutant lung cancer by inhibiting Bim expression
}

\author{
YUNFENG YAO $^{1,2}$, HUILI CHU ${ }^{2}$, JUN WANG $^{2}$ and BAOCHENG WANG ${ }^{1,2}$ \\ ${ }^{1}$ Institute of Post-Graduate, The Second Military Medical University, People's Liberation Army, Shanghai 200433; \\ ${ }^{2}$ Department of Oncology, General Hospital, Jinan Command of The People's Liberation Army, \\ Jinan, Shandong 250031, P.R. China
}

Received October 13, 2017; Accepted August 14, 2018

DOI: 10.3892/ijmm.2018.3835

\begin{abstract}
Primary resistance to epidermal growth factor receptor-tyrosine kinase inhibitors (EGFR-TKIs) is an obstacle for the treatment of non-small cell lung cancer (NSCLC); however, the associated mechanisms are not well understood. Studies have reported that Bim expression levels may be associated with the efficacy of EGFR-TKI treatment in NSCLC patients harboring EGFR mutations. Human antigen $\mathrm{R}(\mathrm{HuR})$ regulates the mRNA and protein expression of target genes, including certain B-cell lymphoma 2 family members. The present study investigated whether HuR mediates resistance to EGFR-TKIs via the regulation of Bim. The results demonstrated that decreased levels of HuR and Bim protein expression are associated with primary resistance to EGFR-TKIs and reduced median progression-free survival in NSCLC patients. In vitro assays also revealed that knockdown of HuR resulted in primary EGFR-TKI resistance and reduced gefitinib-induced apoptosis in HCC827 cells by decreasing Bim expression. Furthermore, elevated HuR expression restored gefitinib sensitivity and enhanced gefitinib-induced apoptosis in $\mathrm{H} 1650$ cells by increasing Bim expression. In vivo, it was further demonstrated that overexpression of HuR was able to restore the gefitinib sensitivity of H1650 cells. Therefore, altered $\mathrm{HuR} / \mathrm{Bim}$ expression is proposed to be a novel mechanism of EGFR-TKI resistance in NSCLC.
\end{abstract}

Correspondence to: Dr Baocheng Wang or Dr Jun Wang, Department of Oncology, General Hospital, Jinan Command of The People's Liberation Army, 25 Shifan Road, Jinan, Shandong 250031, P.R. China

E-mail: baochengwang@hotmail.com

E-mail: ggjun2005@126.com

Key words: Bim, drug resistance, epidermal growth factor receptor mutation, lung cancer, human antigen $\mathrm{R}$

\section{Introduction}

Lung cancer is the leading cause of cancer-associated mortality worldwide, accounting for 158,040 mortalities in 2015, and non-small cell lung cancer (NSCLC) is a common histological subtype of lung carcinoma (1-3). Epidermal growth factor receptor (EGFR) mutations commonly occur in East Asian patients with NSCLC. Approximately $70 \%$ of NSCLC patients with EGFR mutations exhibit a favorable response to tyrosine kinase inhibitors (TKIs), such as gefitinib, when compared with that in patients with wild-type EGFR (4-7). However, drug resistance invariably emerges, and the disease eventually progresses, which is referred to as acquired resistance. The mechanisms underlying acquired resistance to EGFR-TKIs include the T790M gatekeeper mutation, amplification of mesenchymal-epithelial transition and human EGFR 2 (HER2) amplification (8). However, $30 \%$ of patients with EGFR mutations do not exhibit sufficient responses to EGFR-TKIs, which is known as primary resistance (9). Although possible mechanisms have been investigated in several studies, the molecular background of primary resistance remains unknown.

The Bim gene (also known as BCL2L11), which encodes a BH3-only protein, is a pro-apoptotic member of the B-cell lymphoma 2 (Bcl-2) family (10). Overexpression of Bim triggers apoptosis by inducing cytochrome $c$ release (11-13). It has previously been demonstrated that Bim is essential for EGFR-TKI-induced killing of NSCLC cells (14). A recent study further demonstrated that a common Bim deletion polymorphism contributes to poor responses among NSCLC patients with EGFR-mutations treated with EGFR-TKIs (15). Patients with this polymorphism were shown to have a reduced median progression-free survival (mPFS; 6.6 vs. 11.9 months, respectively; $\mathrm{P}=0.003$ ) (16). However, the association between the Bim polymorphism and the response to EGFR-TKIs has not been completely elucidated. By contrast, certain studies have suggested that the presence of this polymorphism is not associated with the efficacy of EGFR-TKIs (17). Faber et al (18) demonstrated that low Bim mRNA expression in cancer specimens accurately predicts the apoptotic response 
to targeted therapies, and confirmed that Bim levels can serve as a correlative marker of EGFR-TKI treatment efficacy.

Human antigen R (HuR) is a widely studied RNA-binding protein that is involved in the regulation of major pathways required for proliferation, apoptosis, differentiation and therapeutic resistance (19). In the cellular context, HuR binds to the 3 -untranslated regions of mRNAs, regulating their stability and translation (20). It has been increasingly reported that HuR is closely associated with the development of numerous types of malignant tumors, including breast (21), colon (22), ovarian (23) and pancreatic cancer $(24,25)$. Furthermore, HuR has been demonstrated to participate in the promotion of chemoresistance by increasing Bcl-2 mRNA stability (19), and HuR displays a good potential for diagnosis and prognosis in cancer.

Therefore, the aim of the present study was to determine whether HuR expression affects the clinical outcomes of NSCLC patients treated with EGFR-TKIs through the modulation of Bim expression.

\section{Materials and methods}

Cell lines. H1650, PC-9 and HCC827 lung cancer cell lines were purchased from the Type Culture Collection of the Chinese Academy of Sciences (Shanghai, China). These cell lines were cultured in RPMI containing $10 \%$ fetal bovine serum. All cells were cultured at $37^{\circ} \mathrm{C}$ in an incubator with $5 \% \mathrm{CO}_{2}$.

Tissue samples. Paraffin-embedded tissue specimens were collected at the General Hospital, Jinan Command of the People's Liberation Army (Jinan, China) between October 2008 and May 2016 (Table I). All the patients involved were diagnosed with adenocarcinoma via biopsy or surgery. Tumor histology and subtypes were classified according to the World Health Organization criteria (26). Eastern Cooperative Oncology Group performance status (ECOG-PS) was used to assess the functional status of patients (27). In addition, the majority of the selected patients were treated with first-line EGFR-TKI treatment. Primary drug resistance was defined as progression within 3 months after the use of EGFR-TKIs, and the sensitive group had a PFS duration of $>6$ months. Informed consent was obtained from all patients, and the study was approved by the Ethics Committee of the General Hospital (Jinan Command of the People's Liberation Army, Jinan, China).

Chemicals and antibodies. Gefitinib was purchased from LC Laboratories (cat. no. G-4408; New Boston, MA, USA), dissolved in dimethyl sulfoxide to a final concentration of $10 \mathrm{mM}$ and stored at $-20^{\circ} \mathrm{C}$. Anti-Bim antibodies used for western blotting were purchased from Cell Signaling Technology, Inc. (cat. no. 2819; Danvers, MA, USA). Anti-HuR and anti- $\beta$-actin antibodies were purchased from Santa Cruz Biotechnology, Inc. (Dallas, TX, USA). All other chemicals were acquired from Sigma-Aldrich (Merck KGaA, Darmstadt, Germany).

RNA interference. Small interfering RNA (siRNA) against HuR was used for RNA interference. The siRNA target sequence for HuR was: 5'-UUUGUCAUGGUCACAAAG
CTT-3'. Briefly, cells were plated at a density of $5 \times 10^{5}$ cells/well in 12-well plates. Using Lipofectamine ${ }^{\circledR} 2000$ reagent (Invitrogen; Thermo Fisher Scientific, Inc.), cells were transfected with $80 \mathrm{nmol} / \mathrm{l}$ siRNA duplex mixture (GeneChem Co., Ltd., Shanghai, China) for $48 \mathrm{~h}$.

Construction, transduction and expression of HuR lentiviral vectors. The HuR gene sequence was amplified by polymerase chain reaction (PCR) using a PrimeScript ${ }^{\mathrm{TM}}$ One Step RT-PCR Kit (Takara Bio, Inc., Otsu, Japan) and then subcloned into a lentiviral expression vector (GV365; GeneChem Co., Ltd.). The PCR primers used for HuR amplification were as follows: HuR forward, 5'-GAGGATCCCCGGGTACCGGTC GCCACCATGTCTAATGGTTATGAAGAC-3' and reverse, 5'-TCCTTGTAGTCCATACCTTTGTGGGACTTGTTGG TTTTG-3'. The thermocycling conditions used for PCR were as follows: Initial denaturation for $5 \mathrm{~min}$ at $98^{\circ} \mathrm{C}$; followed by 30 cycles of denaturation for $10 \mathrm{sec}$ at $98^{\circ} \mathrm{C}$, annealing for $10 \mathrm{sec}$ at $55^{\circ} \mathrm{C}$ and extension for $90 \mathrm{sec}$ at $72^{\circ} \mathrm{C}$; followed by a final extension for $8 \mathrm{~min}$ at $72^{\circ} \mathrm{C}$. Lentiviral packaging plasmids (pHelper 1.0; GeneChem Co., Ltd.) were used for the packaging and production of lentiviral particles. GV365 has a green fluorescent protein (GFP) marker for positive selection. Briefly, H1650 cells were transduced with lentiviral particles as previously described (28), and $\mathrm{H} 1650$ cells that stably expressed high levels of HuR were obtained and subsequently named GV365-H1650 cells. Subsequently, the expression of GFP was observed using fluorescence microscopy, while the expression of $\mathrm{HuR}$ was detected using reverse transcription-quantitative PCR (RT-qPCR) and western blotting.

Cell viability assay. As aforementioned, HCC827 cells were transfected with siRNA targeting HuR for $48 \mathrm{~h}$, and the resultant cells were subsequently names named siHCC827 cells. H1650, GV365-H1650, siHCC827 and HCC827 cells were cultured in 96-well flat-bottomed microliter plates and were allowed to adhere at $37^{\circ} \mathrm{C}$ overnight in $5 \% \mathrm{CO}_{2}$ $\left(\sim 1 \times 10^{4}\right.$ cells/well). After cellular adhesion, gefitinib was added at a final concentration of $0-40 \mu \mathrm{M}$. After $48 \mathrm{~h}$ of incubation, the cytotoxic effects were assessed using the Cell Counting Kit-8 (CCK-8; Beyotime Institute of Biotechnology, Shanghai, China), according to the manufacturer's protocol. Each sample was plated in triplicate.

Apoptosis assays and Annexin $V$ staining. Apoptosis was examined by performing Annexin V and dye exclusion assays. Briefly, cells were simultaneously stained with Annexin V-allophycocyanin (APC; blue staining) and propidium iodide (PI; red staining). This assay was conducted to differentiate between intact ( $\left.\mathrm{APC}^{-} / \mathrm{PI}^{-}\right)$, early apoptotic $\left(\mathrm{APC}^{+} / \mathrm{PI}^{-}\right)$and late apoptotic $\left(\mathrm{APC}^{+} / \mathrm{PI}^{+}\right)$cells. Comparative experiments were performed by bivariate flow cytometry using a FACScan (BD Biosciences, San Jose, CA, USA). Cell Quest software (version 3.3; BD Biosciences, Franklin Lakes, NJ, USA) was used to analyze the obtained data of the cell populations, for which debris was gated out.

RNA isolation and RT-qPCR analyses. Total RNA was isolated from H1650, GV365-H1650, siHCC827 and HCC827 cells using the TRIzol reagent (Invitrogen; Thermo Fisher 
Table I. Patient characteristics and comparison between patients in the EGFR tyrosine kinase inhibitor resistant and sensitive groups.

\begin{tabular}{|c|c|c|c|}
\hline & Resistant group (n=27) & Sensitive group $(\mathrm{n}=54)$ & P-value \\
\hline Sex, $\mathrm{n}$ & & & 0.01 \\
\hline Male & 22 & 23 & \\
\hline Female & 5 & 31 & \\
\hline Age (years), $n$ & & & 0.343 \\
\hline$\geq 60$ & 13 & 32 & \\
\hline$<60$ & 14 & 22 & \\
\hline ECOG PS, n & & & 0.717 \\
\hline Score 0-2 & 26 & 51 & \\
\hline Score 3 & 1 & 3 & \\
\hline EGFR mutation, $\mathrm{n}$ & & & 0.501 \\
\hline Exon 19 deletion & 17 & 38 & \\
\hline L858R mutation & 10 & 16 & \\
\hline Tumor stage, $\mathrm{n}$ & & & 0.069 \\
\hline IIIa & 1 & 6 & \\
\hline IIIb & 1 & 7 & \\
\hline IV & 25 & 41 & \\
\hline Surgical history, $\mathrm{n}$ & & & 0.392 \\
\hline Yes & 3 & 10 & \\
\hline No & 24 & 44 & \\
\hline Chemoradiotherapy history, $n$ & & & 0.270 \\
\hline Yes & 17 & 27 & \\
\hline No & 10 & 27 & \\
\hline Brain metastases, $\mathrm{n}$ & & & 0.089 \\
\hline Yes & 3 & 15 & \\
\hline No & 24 & 39 & \\
\hline
\end{tabular}

The resistant group exhibited progression within 3 months of treatment, while the sensitive group exhibited progression-free survival for $>6$ months. EGFR, epidermal growth factor receptor; ECOG PS, Eastern Cooperative Oncology Group performance status.

Scientific, Inc., Waltham, MA, USA) in accordance with the manufacturer's instructions. Isolated RNA was reverse-transcribed into cDNA using PrimeScript ${ }^{\mathrm{TM}}$ RT reagent kit with gDNA Erase (Takara Bio, Inc.). To investigate the expression of target genes, qPCR was performed in triplicate using an ABI Step One Plus Detection System (Applied Biosystems; Thermo Fisher Scientific, Inc.) using SYBR ${ }^{\circledR}$ Premix Ex Taq ${ }^{\mathrm{TM}}$ (Takara Bio, Inc.) in a $25 \mu \mathrm{l}$ reaction with $900 \mathrm{nM}$ primers. qPCR thermocycling conditions were as follows: Initial denaturation for $30 \mathrm{sec}$ at $95^{\circ} \mathrm{C}$; followed by 40 cycles at $95^{\circ} \mathrm{C}$ for $5 \mathrm{sec}$ and $60^{\circ} \mathrm{C}$ for $30 \mathrm{sec}$. The PCR primers for HuR, Bim or $\beta$-actin were as follows: HuR forward, 5'-ACATGACCCAGG ATGAGTTACGAAG-3', and reverse, 5'-TCGCGGTCACGT AGTTCACAA-3'; Bim forward, 5'-TGATTCTTGCAGCCA CCCTG-3', and reverse, 5'-GGGGAACAAGGGCCAAGA AA-3'; $\beta$-actin forward, 5'-TGGCACCCAGCACAATGAA-3', and reverse, 5'-CTAAGTCATAGTCCGCCTAGAAGCA-3'. The relative quantification of $\mathrm{HuR}$ and Bim expression was calculated using the $2^{-\Delta \Delta \mathrm{Cq}}$ method (29), and normalized to $\beta$-actin expression.
Western blotting. Cells were lysed with lysis buffer (Beyotime Institute of Biotechnology), and the precipitated cell debris was discarded by centrifugation at $4^{\circ} \mathrm{C}$ for $15 \mathrm{~min}(1,200 \mathrm{x} \mathrm{g})$. The protein concentration was then determined using a Bradford protein assay kit (Bio-Rad Laboratories, Inc., Hercules, CA, USA). Protein samples (30-50 $\mu \mathrm{g} / \mathrm{lane})$ were separated on a $2.5 \%$ SDS-PAGE gel and then transferred to polyvinylidene difluoride membranes. Following this, membranes were blocked with $5 \%(\mathrm{w} / \mathrm{v})$ non-fat dry milk in $1 \mathrm{X}$ Tris buffered saline with $0.1 \%$ Tween 20 for $3 \mathrm{~h}$ at $37^{\circ} \mathrm{C}$ and then incubated overnight at $4^{\circ} \mathrm{C}$ with primary antibodies against the following proteins: HuR (cat. no. sc-5261; 1:1,000) and GAPDH (cat. no. sc-20358; 1:1,000) were purchased from Santa Cruz Biotechnology, Inc.; and antibodies against Bim (cat. no. 2819; 1:2,000) were procured from Cell Signaling Technology, Inc. Following this, the membranes were washed and incubated with the following secondary antibodies for $1 \mathrm{~h}$ at $25^{\circ} \mathrm{C}$ : HRP-tagged rabbit anti-mouse $\mathrm{IgG}$ (cat. no. sc-358920; 1:2,000; Santa Cruz Biotechnology, Inc.), HRP-conjugated donkey anti-goat IgG-HRP (cat. no. sc-2020; 
1:5,000; Santa Cruz Biotechnology, Inc.) and HRP-conjugated mouse anti-rabbit IgG (cat. no. A01827-200; 1:5,000; Genscript, Piscataway, NJ, USA). The blots were visualized using an enhanced chemiluminescence kit (Beyotime Institute of Biotechnology, Shanghai, China). Images were captured using Scion image software (version 4.0.3.2; Scion Corporation, Frederick, MD, USA).

Immunohistochemical (IHC) analysis. Formalin-fixed, paraffin-embedded tissues collected from patients with NSCLC $(n=81)$ were sectioned at $5 \mathrm{~mm}$. Briefly, tissue sections were incubated at $60^{\circ} \mathrm{C}$ for $2 \mathrm{~h}$, deparaffinized, rehydrated in a descending alcohol series and subsequently blocked with $3 \%$ hydrogen peroxide for $30 \mathrm{~min}$ at room temperature. Following incubation with sodium citrate buffer $(0.01 \mathrm{M})$ at room temperature for $30 \mathrm{~min}$, the sections were then preincubated in $10 \%$ normal goat serum (Beyotime Institute of Biotechnology) at room temperature for $30 \mathrm{~min}$ to prevent non-specific staining. Subsequently, the sections were incubated overnight at $4^{\circ} \mathrm{C}$ with antibodies against HuR (cat. no. sc-5261; 1:1,000; Santa Cruz Biotechnology, Inc.) and Bim (cat. no. 2819; 1:1,000; Cell Signaling Technology, Inc.). Following this, sections were then incubated with corresponding horseradish peroxidase (HRP)-tagged secondary antibodies (cat. no. sc-358920, 1:1,000; and cat. no. sc-2020, 1:2,000; Santa Cruz Biotechnology, Inc.) for $30 \mathrm{~min}$ at room temperature. Two pathologists individually examined the levels of IHC signaling under a light microscope (magnification, x200). The algorithm output returns a number of quantitative measurements, namely the intensity and percentage of positive staining present (30). Subsequently, the staining intensity and percentage of positive staining were categorized into 4 and 5 classes, respectively, following the determination of cut-off values, according to a previously published protocol (30). The intensity of staining was categorized as 0 (no staining), $1+$ (weak staining), 2+ (moderate staining) and 3+ (strong staining). In each sample, five high-power fields were selected, and the specimens were categorized into five semi-quantitative classes based on percentage of positive staining as follows: $0(<5 \%$ stained cells), 1 (6-25\% stained cells), 2 (26-50\% stained cells), 3 (51-75\% stained cells) and 4 ( $>76 \%$ stained cells). The products of percent positive and intensity scores yielded final IHC scores of $<2$ (negative) and $>2$ (positive).

In vivo animal model experiments. A total of 14 healthy female $\mathrm{BALB} / \mathrm{c}$ nude mice (aged 4 weeks old, weighing 14.6-21.8 g) were purchased from Beijing Vital River Laboratory Animal Technology Co., Ltd. (Beijing, China) and subsequently housed at $21^{\circ} \mathrm{C}$ and $50-55 \%$ humidity with a $14 / 10 \mathrm{~h} \mathrm{light/dark} \mathrm{cycle}$ under germ-free (GF) conditions at the Laboratory Animal Research Center in General Hospital, Jinan Command of the People's Liberation Army. Mice were permitted to acclimatize for 1 week post-arrival. Mice received a standard laboratory chow and water ad libitum. For experiments assessing the effect of drug treatment on tumor growth, 10 female BALB/c nude mice were selected. The mice were randomized into two groups, including the transfection and control groups. In the transfection and control groups, GV365-H1650 cells or non-transfected $\mathrm{H} 1650$ cells were respectively injected into the back of BALB/c nude mice. The xenograft size was measured every 3 days, and the tumor volume was determined as follows: (length $\mathrm{x}$ width $^{2}$ )/2. A total of 2 weeks post-tumor implantation (all tumors were $\geq 500 \mathrm{~mm}^{3}$ in volume), gefitinib $(5 \mathrm{mg} / \mathrm{kg}$ ) was administrated once a day via intragastric administration for a total of 15 days. Animal welfare and relevant experiments were conducted in compliance with the Guide for the Care and Use of Laboratory Animals (Animal Scientific Procedures, SAC/TC281), and were approved by the Ethics Committee of the General Hospital, Jinan Command of the People's Liberation Army.

Statistical analysis. The correlation of HuR and Bim staining with the different clinicopathological features of patients was evaluated using the $\chi^{2}$ test. Univariate survival analysis was calculated using the Kaplan-Meier Method. Significance of the data was analyzed by the log-rank test. A P-value of $<0.05$ was considered to indicate a difference that was statistically significant, and all P-values were two-sided. All statistical calculations were performed using the SPSS statistical software (version 18.0; SPSS, Inc., Chicago, IL, USA).

\section{Results}

Negative expression of HuR and Bim correlates with lower EGFR-TKI sensitivity in tumor tissues obtained from EGFR-mutant NSCLC patients. The associations between $\mathrm{HuR}$ and Bim expression levels and clinicopathological characteristics of patients with NSCLC were determined using $\chi^{2}$ tests. There was an evident difference in terms of the sex between the two groups of patients. Female patients accounted for $18.5 \%$ of cases in the resistant group, whereas they comprised $57.4 \%$ of the sensitive group cases, and this different was statistically significant $(\mathrm{P}=0.01$; Table I). However, there were no significant differences between the EGFR-TKI-sensitive group and EGFR-TKI-resistant group with respect to the age, ECOG-PS (27), mutation type, tumor stage, surgery or chemoradiotherapy history, and brain metastases ( $\mathrm{P}>0.05$; Table I) (31).

For HuR staining, $81.5 \%$ (22 out of 27) cytoplasm-negative and $18.5 \%$ ( 5 out of 27 ) cytoplasm-positive specimens were identified in the EGFR-TKI-resistant group, whereas 20.4\% (11 out of 54) specimens were cytoplasm-negative and $79.6 \%$ (43 out of 54) were cytoplasm-positive in the EGFR-TKI-sensitive group. These results indicated that IHC staining for HuR was higher in the EGFR-TKI-sensitive group as compared with that in the EGFR-TKI-resistant group ( $\mathrm{P}<0.001$; Table II). For Bim staining, 70.4\% (19 out of 27) cytoplasm-negative and $29.6 \%$ (8 out of 27) cytoplasm-positive specimens were detected in the EGFR-TKI-resistant group, whereas $7.4 \%$ (4 out of 54) cases were cytoplasm-negative and $92.6 \%$ (50 out of 54) were cytoplasm-positive in the EGFR-TKI-sensitive group. These findings indicated that IHC staining for Bim was also higher in the EGFR-TKI-sensitive group as compared with that in the EGFR-TKI-resistant group ( $\mathrm{P}<0.001$; Table II). Therefore, the altered expression of HuR and Bim may modulate the therapeutic effect of EGFR-TKIs in NSCLC and serve as an important index for the treatment of this disease.

Association among HuR expression, Bim expression and clinicopathological variables. The correlation of Bim 
Table II. Expression levels of HuR and Bim in epidermal growth factor receptor-tyrosine kinase inhibitor resistant and sensitive groups.

\begin{tabular}{|c|c|c|c|c|}
\hline Cytoplasmic expression & Resistant group $(\mathrm{n}=27)(\%)$ & Sensitive group $(n=54)(\%)$ & $\chi^{2}$ value & P-value \\
\hline HuR, n (\%) & & & 84 & $<0.001$ \\
\hline Negative & $22(81.5)$ & $11(20.4)$ & & \\
\hline Positive & $5(18.5)$ & $43(79.6)$ & & \\
\hline Bim, n (\%) & & & 10 & $<0.001$ \\
\hline Negative & $19(70.4)$ & $4(7.4)$ & & \\
\hline Positive & $8(29.6)$ & $50(92.6)$ & & \\
\hline
\end{tabular}

HuR, human antigen $\mathrm{R}$.

Table III. Correlation between the expression levels of HuR and Bim in all patients.

\begin{tabular}{|c|c|c|c|c|c|}
\hline \multirow[b]{2}{*}{ HuR expression } & \multicolumn{2}{|c|}{ Bim expression } & \multirow[b]{2}{*}{ Total } & \multirow[b]{2}{*}{ Positive rate $(\%)$} & \multirow[b]{2}{*}{ P-value } \\
\hline & Positive (\%) & Negative (\%) & & & \\
\hline Positive (\%) & $46(95.8)$ & $2(4.2)$ & 48 & 95.8 & $\begin{array}{l}\mathrm{P}<0.01 \\
\mathrm{P}<0.05\end{array}$ \\
\hline Negative (\%) & $12(36.4)$ & $21(63.6)$ & 33 & 36.4 & \\
\hline Total & 58 & 23 & 81 & 71.6 & \\
\hline
\end{tabular}

HuR, human antigen R.

Table IV. Correlation of cytosolic Bim staining with the clinicopathological features and cytoplasmic HuR expression in the EGFR-tyrosine kinase inhibitor resistant group.

\begin{tabular}{|c|c|c|c|c|}
\hline Clinicopathological features & Total $(n=27)$ & Negative Bim taining & $\chi^{2}$ value & P-value \\
\hline Sex, $n$ & & & 1.877 & 0.221 \\
\hline Male & 22 & 19 & & \\
\hline Female & 5 & 3 & & \\
\hline Age (years), $\mathrm{n}$ & & & 0.345 & 0.648 \\
\hline$\geq 60$ & 13 & 10 & & \\
\hline$<60$ & 14 & 12 & & \\
\hline EGFR mutation, $\mathrm{n}$ & & & 3.610 & 0.124 \\
\hline Exon 19 deletion & 17 & 12 & & \\
\hline L858R mutation & 10 & 10 & & \\
\hline HuR staining & & & 372 & 0.010 \\
\hline Positive & 5 & 1 & & \\
\hline Negative & 22 & 21 & & \\
\hline
\end{tabular}

EGFR, epidermal growth factor receptor; HuR, human antigen R.

expression with HuR expression in NSCLC patients was analyzed by performing $\chi^{2}$ tests. In patients with a positive expression of $\mathrm{HuR}$, the positive rate of Bim was significantly higher (95.8 vs. $4.2 \%, \mathrm{P}<0.01)$. In addition, the Bim negative expression rate was significantly higher in patients with negative HuR expression (63.6 vs. 36.4\%, $\mathrm{P}<0.05)$, proving the existence of correlation between HuR and Bim expression (Table III). Notably, among the 27 cases with interpretable HuR and Bim staining, negative Bim expression was associated with negative cytoplasmic HuR expression ( $\mathrm{P}=0.01$; Table IV). However, Bim status was not correlated with the sex, age or mutation type ( $\mathrm{P}>0.05$; Table IV). 

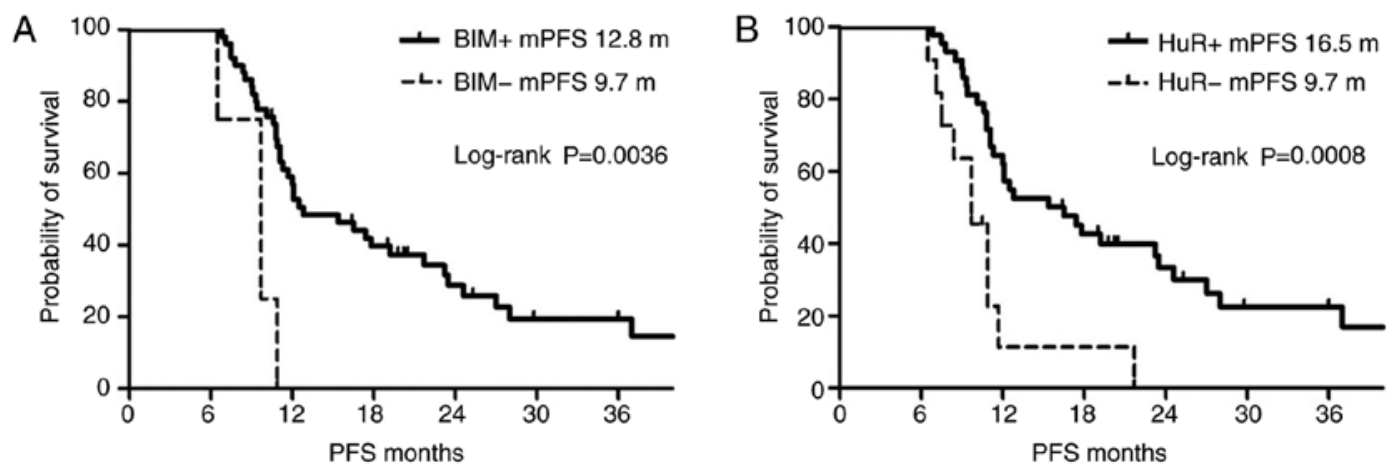

Figure 1. Bim and HuR expression levels in 54 non-small cell lung cancer tissues, and their association with PFS. Kaplan-Meier curves depicted the PFS according to the expression of (A) Bim and (B) HuR. HuR, human antigen R; PFS, progression-free survival.
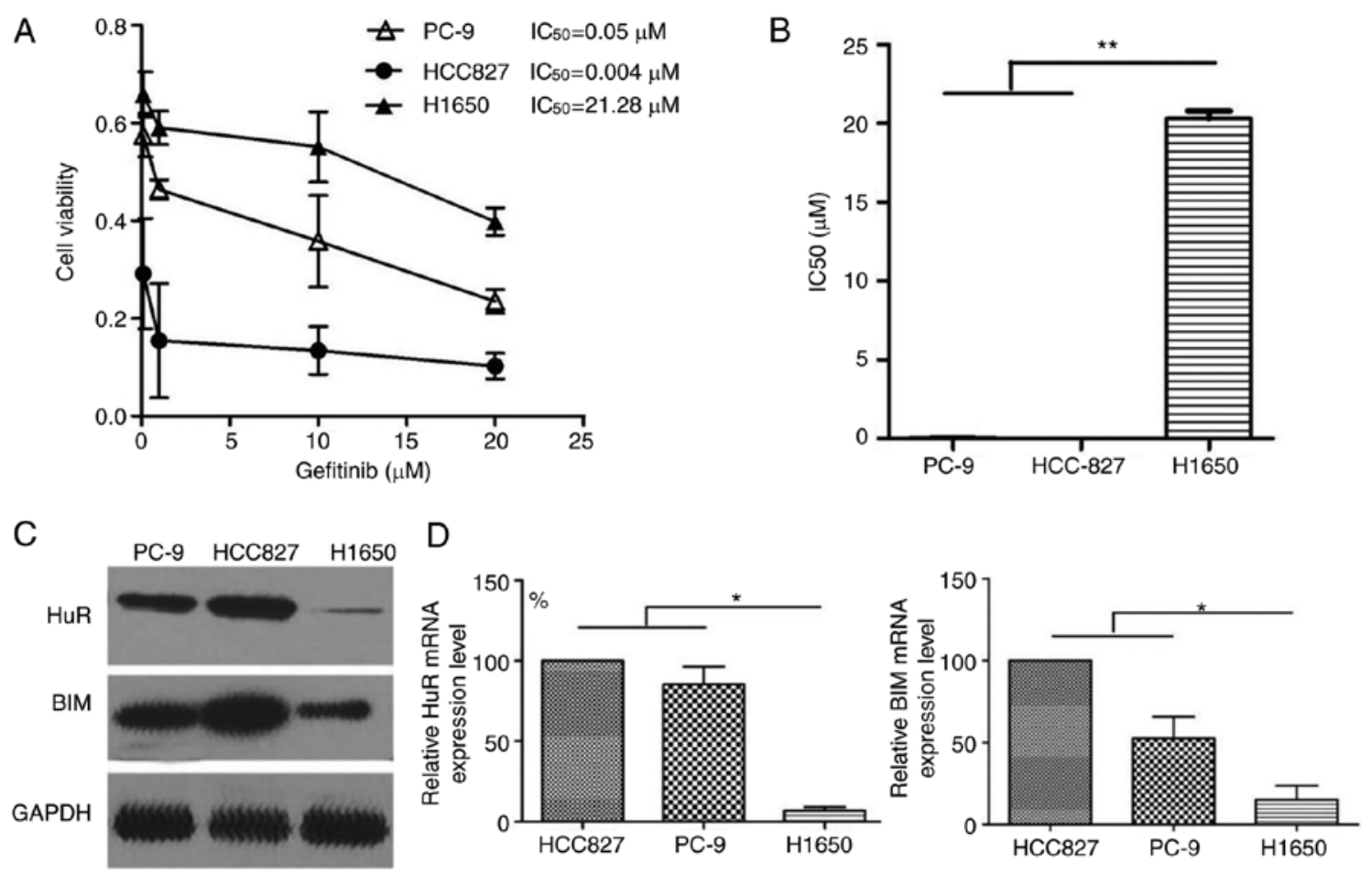

Figure 2. Gefitinib-resistant cells display altered expression profiles of HuR and Bim. (A) Three non-small cell lung cancer cell types were treated with gefitinib for $48 \mathrm{~h}$, and then dose-response curves were used to calculate the $\mathrm{IC}_{50}$ using Cell Counting Kit- 8 assay. (B) Comparison of the $\mathrm{IC}_{50}$ values of three cell lines. (C) Comparison of the HuR and Bim protein expression levels in the three cell lines using western blotting. (D) HuR and Bim mRNA levels were quantified by reverse transcription-quantitative polymerase chain reaction in the three cell lines, and normalized to $\beta$-actin levels. ${ }^{*} \mathrm{P}<0.05$ and ${ }^{* * *} \mathrm{P}<0.01$, vs. the PC-9 and HCC827 groups, as determined by the least significant difference test. HuR, human antigen $\mathrm{R}$; $\mathrm{IC}_{50}$, half maximal inhibitor concentration.

Negative HuR and Bim expression is associated with reduced PFS in patients in the sensitive group undergoing EGFR-TKI treatment. In the EGFR-TKI-sensitive group, the mPFS was 12.8 months for patients with positive Bim expression and 9.7 months for patients with negative Bim expression. The mPFS of patients with positive Bim expression was significantly higher in comparison with that of patients with negative Bim expression, based on Kaplan-Meier analysis $(\mathrm{P}=0.0036$; Fig. 1). By contrast, the mPFS was 16.5 months for patients with positive HuR expression and 9.7 months for patients with negative HuR expression in the EGFR-TKI-sensitive group; thus, patients with positive HuR expression exhibited a significantly longer mPFS based on Kaplan-Meier analysis ( $\mathrm{P}=0.0008$; Fig. 1).
Gefitinib-resistant cells display altered expression of $\mathrm{HuR}$ and Bim. To determine whether HuR and Bim expression were implicated in gefitinib resistance, three EGFR-mutant lung cancer cell lines, namely PC9, HCC827 and H1650, were used in the present study. CCK- 8 assays were performed to determine the half maximal inhibitor concentration $\left(\mathrm{IC}_{50}\right)$ for gefitinib. The $\mathrm{IC}_{50}$ value for gefitinib in the $\mathrm{H} 1650$ cells was $21.28 \mu \mathrm{M}$. By contrast, HCC 827 and PC-9 cells exhibited significantly lower $\mathrm{IC}_{50}$ values for gefitinib ( 0.05 and $0.004 \mu \mathrm{M}$, respectively; Fig. 2A and B). Western blot analysis revealed an evident downregulation of HuR and Bim levels in gefitinib-resistant H1650 cells (Fig. 2C). The determination of mRNA levels for these genes led to similar conclusions. Indeed, H1650 cells exhibited reduced HuR levels by 10 -fold and reduced Bim 
A
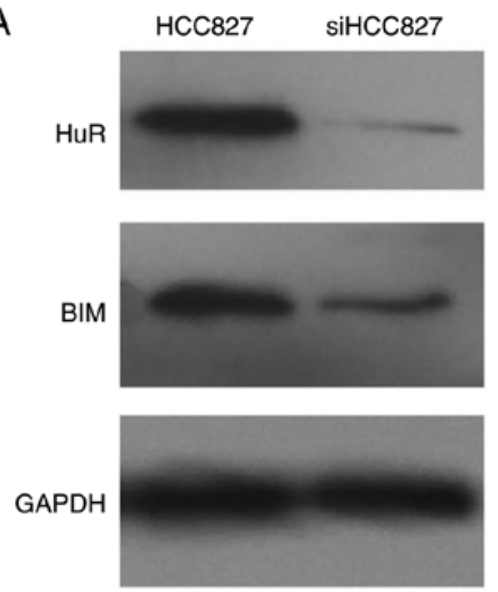

C

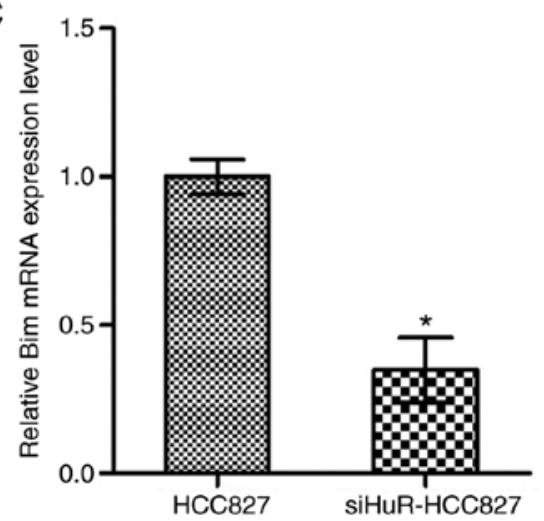

B

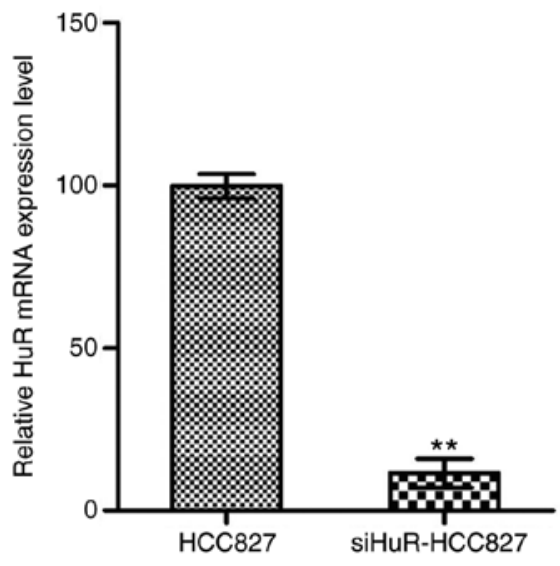

D

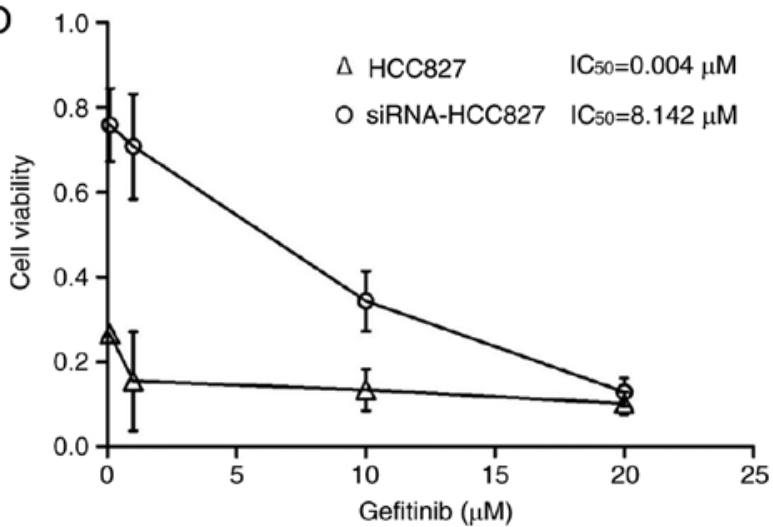

Figure 3. Decreased HuR expression confers primary tyrosine kinase inhibitor resistance in HCC827 cells by inhibiting Bim expression. (A) siRNA was used to interfere with HuR expression in HCC827 cells. Western blotting showing the expression levels of proteins and the loading control GAPDH. (B) HuR and (C) Bim mRNA levels were quantified using reverse transcription-quantitative polymerase chain reaction in siHuR-HCC827 and HCC827 cells, and normalized to the expression of $\beta$-actin. (D) Following gefitinib treatment for $48 \mathrm{~h}$, dose-response curves were used to calculate the IC ${ }_{50}$ using a Cell Counting Kit- 8 assay. ${ }^{*} \mathrm{P}<0.05$ and ${ }^{* *} \mathrm{P}<0.01$ vs. the HCC827 group, as determined by the independent sample t-test. HuR, human antigen R; siRNA, small interfering RNA; $\mathrm{IC}_{50}$, half maximal inhibitor concentration.

levels by 5-fold, as compared with those in parental HCC827 cells (Fig. 2D). According to the differential expression levels of $\mathrm{HuR}$, in subsequent experiments, expression levels of HuR were downregulated in HCC827 cells via siRNA interference. Meanwhile, expression levels of HuR were upregulated in H1650 cells transfected with HuR lentiviral vectors.

Knockdown of HuR confers primary EGFR-TKIresistance and a reduction in gefitinib-induced apoptosis in HCC 827 cells by decreasing Bim expression. The results of the current study revealed that HuR and Bim were upregulated in HCC827 cells compared with their expression levels in H1650 cells. Since HCC827 cells had the lowest $\mathrm{IC}_{50}$ value for gefitinib, it is hypothesized that altered expression of HuR/Bim serves an important role in modulating gefitinib sensitivity in EGFR-mutant lung cancer cells. The study next examined HCC827 cells to determine whether lower expression of HuR promotes gefitinib resistance. In HCC827 cells, HuR expression was downregulated via siRNA interference. As expected, RT-qPCR and western blotting data indicated that HuR expression decreased significantly following HuR knockdown as compared with the levels in control cells (Fig. 3A-C). Furthermore, a CCK-8 assay kit was used to detect gefitinib sensitivity at $48 \mathrm{~h}$ after transfection, revealing that the cell viability increased in
HuR-knockdown HCC827 cells compared with that in control HCC 827 cells. The results revealed that the cell viability of siHuR-HCC827 cells was markedly increased compared with control HCC827 cells (Fig. 3D). Annexin V/PI staining also demonstrated a marked decrease in gefitinib-induced apoptosis in the HuR-knockdown HCC827 cells compared with that in control cells (Fig. 4).

The effect of HuR knockdown in HCC827 cells on Bim expression was also examined. Western blotting and RT-qPCR were used to detect the expression of Bim protein and mRNA in $\mathrm{HCC} 827$ cells, respectively. The expression levels of Bim protein and mRNA were significantly decreased in the HuR-knockdown group in comparison with that in the control group $(\mathrm{P}<0.01$; Fig. 3).

Elevated expression of HuR restores gefitinib sensitivity and enhances gefitinib-induced apoptosis in H1650 cells by increasing Bim expression. As mentioned earlier, the expression of HuR was lower in H1650 cells. Next, these cells were used to determine whether a higher expression of HuR was able to restore gefitinib sensitivity by manipulating Bim expression using a HuR lentiviral expression vector. HuR and Bim expression levels in infected and control cells were then examined using western blotting and RT-qPCR. Western 


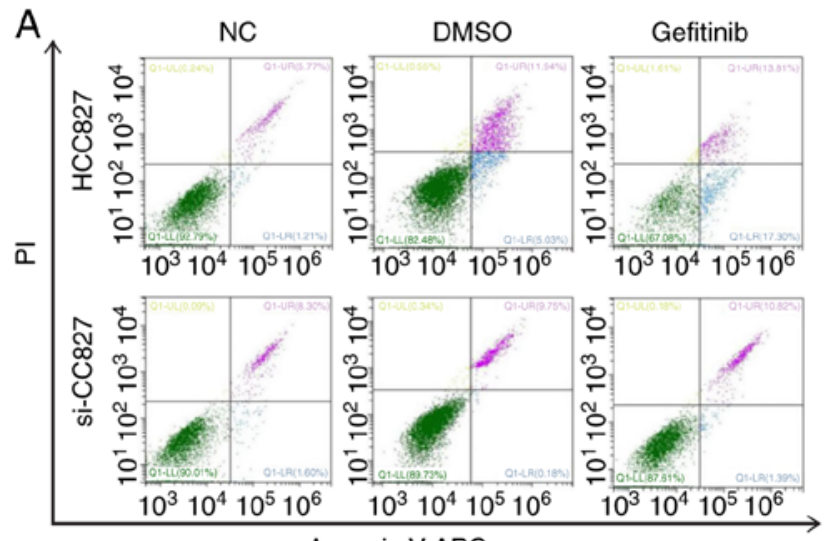

B

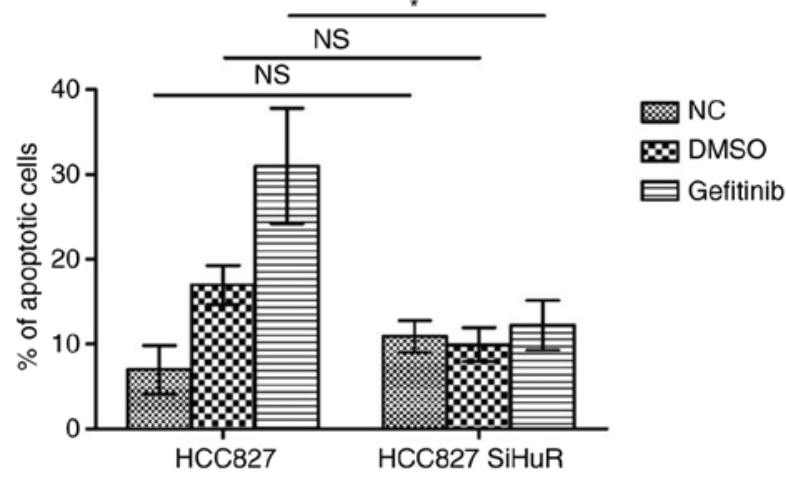

Figure 4. Inhibition of HuR decreases the apoptosis of HCC827 cells. (A) Following incubation with $0.1 \%$ DMSO or $10 \mu \mathrm{M}$ gefitinib for $48 \mathrm{~h}$, siHuR-HCC827 and HCC827 cells were subjected to Annexin V and PI staining, followed by flow cytometric analysis. (B) Percentage of apoptotic cells, assessed using a flow cytometric analyzer. " $\mathrm{P}<0.05$ vs. the HCC 827 group, as determined by the least significant difference test. HuR, human antigen R; PI, propidium iodide; NC, negative control; DMSO, dimethyl sulfoxide; ns, not significant.

A

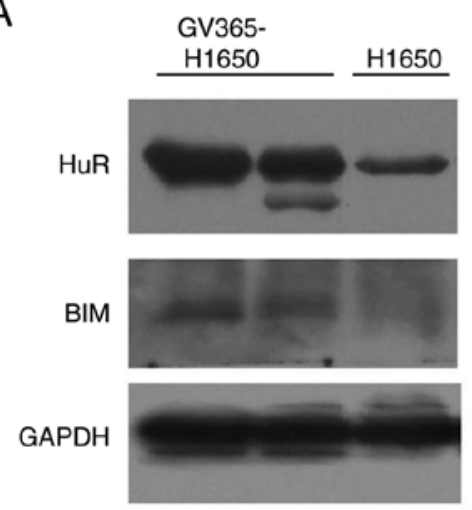

C

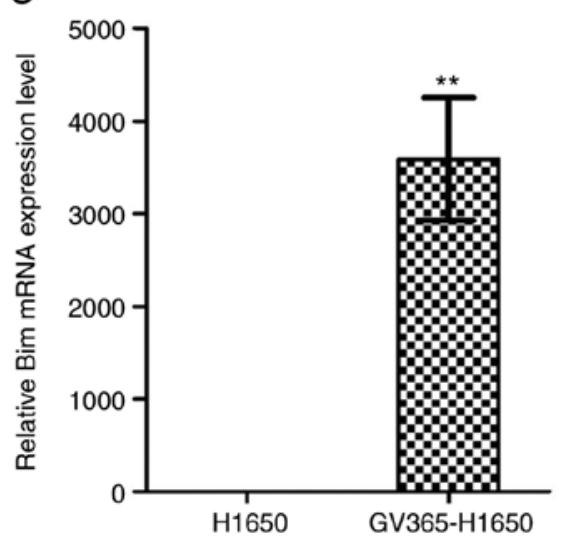

B

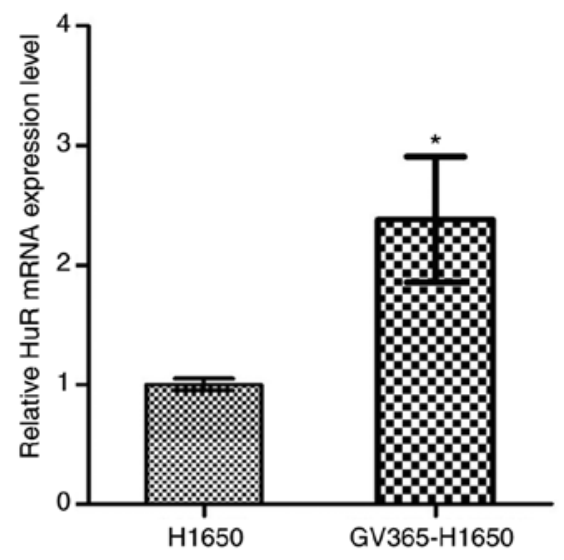

D

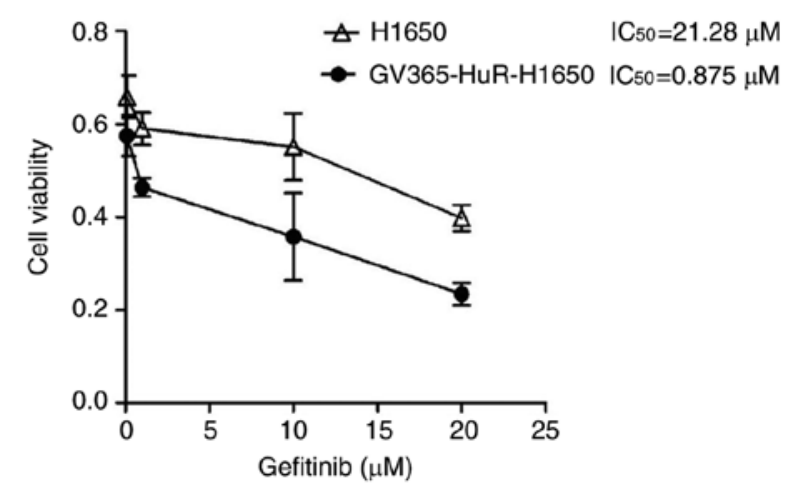

Figure 5. Increased HuR expression restores the response to gefitinib in H1650 cells by increasing Bim expression. (A) H1650 cells were transfected with the GV365-HuR vector for overexpression of HuR. Western blot analyses displaying the expression of HuR, Bim and the loading control GAPDH. (B) HuR and (C) Bim mRNA levels were quantified by reverse transcription-quantitative polymerase chain reaction in GV365-H1650 and H1650 cells, and normalized to $\beta$-actin levels. (D) Following gefitinib treatment for $48 \mathrm{~h}$, dose-response curves were used to calculate the $\mathrm{IC}_{50}$ using a Cell Counting Kit- 8 assay. "P<0.05 and ${ }^{* *} \mathrm{P}<0.01$, vs. the $\mathrm{H} 1650$ group, as determined by independent sample t-test. HuR, human antigen $\mathrm{R} ; \mathrm{IC}_{50}$, half maximal inhibitor concentration.

blotting indicated that the protein expression of HuR and Bim was increased with lentiviral infection (Fig. 5A). HuR and Bim mRNA levels were also significantly higher in the H1650 infected group as compared with those in the control group $(\mathrm{P}<0.01$; Fig. 5B and $\mathrm{C})$. The results revealed that the cell viability of GV365-H1650 cells was markedly decreased compared with the control H1650 cells (Fig. 5D). Furthermore, Annexin V/PI staining indicated that HuR overexpression increased the apoptosis rates when compared with those in control cells (Fig. 6). 
A

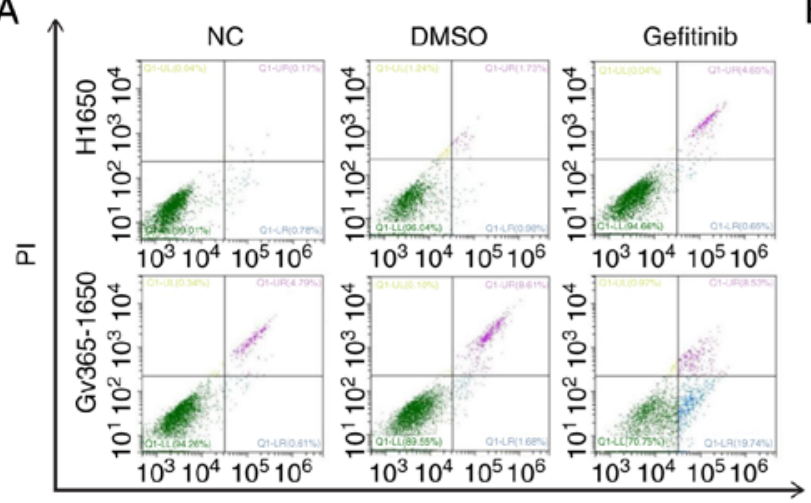

Annexin V-APC
B

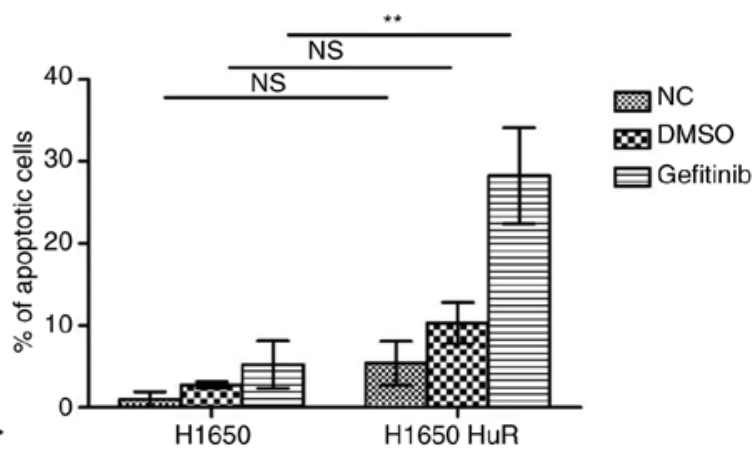

Figure 6. HuR overexpression increases the apoptosis of H1650 cells. (A) Following incubation with $0.1 \%$ DMSO or $10 \mu$ M gefitinib for 48 h, GV365-HuR-H1650 and H1650 cells were subjected to Annexin V and PI staining, followed by flow cytometric analysis. (B) Percentage of apoptotic cells, assessed using a flow cytometric analyzer. ${ }^{* *} \mathrm{P}<0.01$ vs. the $\mathrm{H} 1650$ group, as determined by the least significant difference test. HuR, human antigen R; PI, propidium iodide; NC, negative control; DMSO, dimethyl sulfoxide; ns, not significant.

A
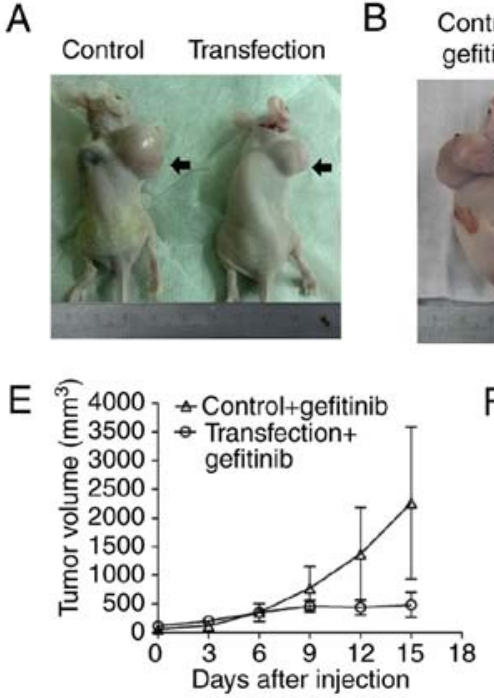

B

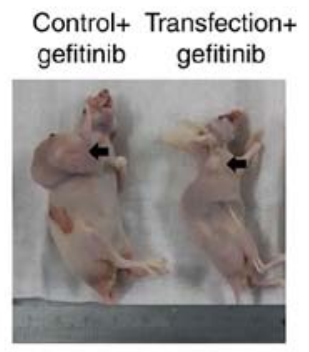

$\mathrm{F}$
C

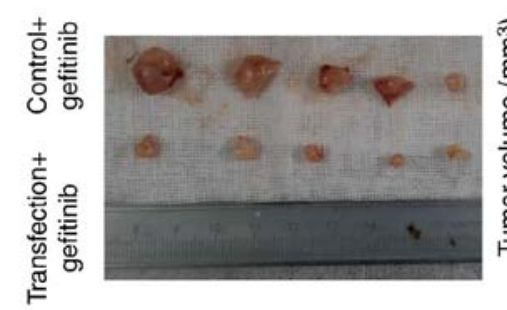

G

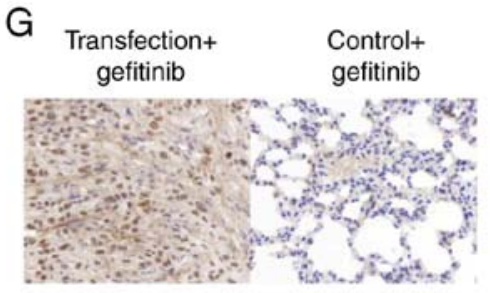

Figure 7. Increasing HuR expression restores gefitinib sensitivity in H1650 cells in vivo. Comparison of engrafted tumors in mice injected with HuR-overexpressing H1650 cells and control H1650 cells at two time points: (A) without treatment (at day 15), and (B) at 15 days after treatment with gefitinib $(100 \mathrm{mg} / \mathrm{kg})$. The images show a representative mouse with the largest tumor in each group. (C) Comparison of engrafted tumors of five nude mice in each group following treatment with gefitinib. The largest diameter of the xenografts in the control + gefitinib and the transfection + gefitinib groups was 1.2 and $0.5 \mathrm{~cm}$ (at day 15), respectively. (D) Comparison of engrafted tumor volumes following treatment with gefitinib. ${ }^{* *} \mathrm{P}<0.01 \mathrm{vs}$. the control + gefitinib group, as determined by the independent sample t-test. (E) Corresponding tumor growth curves after gefitinib treatment. Xenograft size was measured every 3 days. Values (mean \pm standard error; $\mathrm{mm}^{3}$ ) were calculated from the tumor volume of five mice in each group. $(\mathrm{F}) \mathrm{HuR}$ and $(\mathrm{G})$ Bim expression levels in the engrafted tumors of each group were tested by immunohistochemistry. HuR, human antigen R; control, xenografts formed by injection of H1650 cells; transfection, xenografts formed by injection of HuR-overexpressing H1650 cells.

H1650xenograft tumorburden is nearly suppressed by gefitinib treatment with HuR overexpression. Prior to the administration of gefitinib treatment, xenograft tumors originating from the HuR-overexpressing H1650 stable clone and control clone exhibited continued and rapid growth. As shown in Fig. 7A, the size of tumors in the two groups 15 days post-treatment grew rapidly, with no significant difference between the two groups without gefitinib. By contrast, when gefitinib treatment was administered for 15 days in mice with xenograft tumors, the tumor burden induced by HuR-overexpressing H1650 cells was evidently suppressed by gefitinib in comparison with that in the control group (Fig. 7B). In addition, suppression of the tumor burden in the transfection + gefitinib group continued for 15 days. However, the tumor burden induced by the control + gefitinib clone was not evidently changed following gefitinib treatment. Tumor volumes in the transfection + gefitinib group were significantly smaller in comparison with those in the control + gefitinib group (Fig. 7C and D). The growth trend of xenograft tumors in each group exhibited an upward trend; however, the growth increase in the transfection + gefitinib group was significantly slower compared with that of the control + gefitinib group (Fig. 7E; Table V). IHC analysis further revealed that HuR expression was significantly increased and that Bim expression was simultaneously elevated in transfection + gefitinib group following gefitinib treatment (Fig. 7F and G). 
A

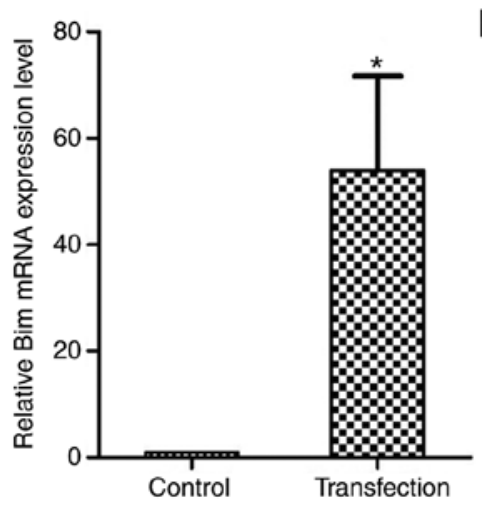

$\mathrm{B}$

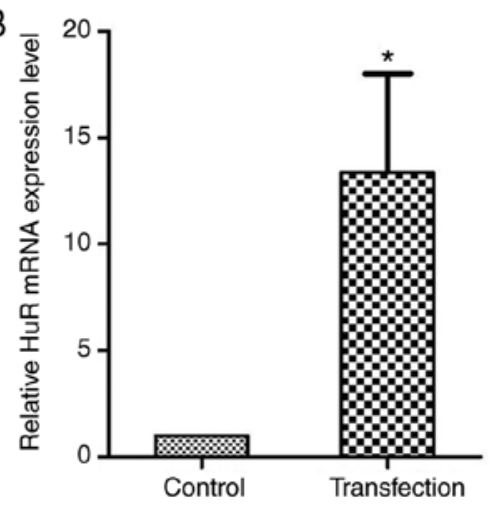

C

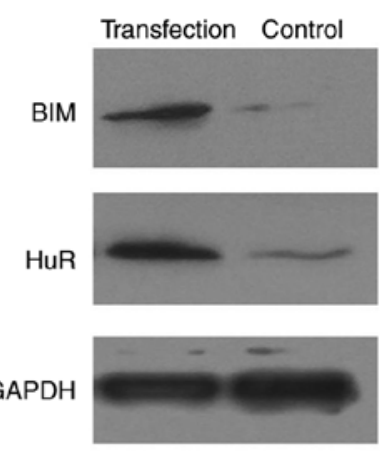

Figure 8. Increased HuR expression confers restored response to gefitinib in vivo by increasing Bim expression. (A) HuR and (B) Bim mRNA levels were quantified by reverse transcription-quantitative polymerase chain reaction in HuR-transduced tumor engraftments and in the control group following gefitinib treatment, and were normalized to $\beta$-actin levels. ${ }^{*} \mathrm{P}<0.05$ vs. the control group. (C) Western blot analyses displaying the expression levels of target proteins and the loading control GAPDH following gefitinib treatment. HuR, human antigen R; control, xenografts formed by injection of H1650 cells; transfection, xenografts formed by injection of HuR-overexpressing H1650 cells.

Table V. Volume of xenograft tumors in the two groups subsequent to gefitinib treatment, examined at 3-day intervals (mean \pm standard error of the mean).

\section{Volume $\left(\mathrm{mm}^{3}\right)$}

Day Control+gefitinib Transfection +gefitinib P-value

\begin{tabular}{rcll}
\hline 0 & $00 \pm 26.49$ & $112.57 \pm 72.35$ & 0.093 \\
3 & $118.64 \pm 47.90$ & $200.29 \pm 62.10$ & 0.017 \\
6 & $349.79 \pm 153.93$ & $347.36 \pm 68.54$ & 0.970 \\
9 & $771.71 \pm 375.42$ & $455.07 \pm 98.86$ & 0.041 \\
12 & $1,369.43 \pm 811.87$ & $437.43 \pm 126.81$ & 0.012 \\
15 & $2,260.28 \pm 1,322.97$ & $479.14 \pm 216.38$ & 0.004 \\
\hline
\end{tabular}

Control, xenografts formed by injection of H1650 cells; transfection, xenografts formed by injection of HuR-overexpressing H1650 cells.

HuR and Bim expression levels were next measured by western blotting and RT-qPCR in the transplanted tumors. The levels of HuR and Bim were significantly higher in the transduction + gefitinib group as compared with the control + gefitinib group following gefitinib treatment (Fig. 8). These results strongly support the mechanism implied by the cell model, and suggest that HuR-mediated Bim overexpression confers EGFR-TKI resistance.

\section{Discussion}

The present study demonstrated that different HuR expression levels may explain the contradictory findings regarding the EGFR-TKI clinical outcomes; specifically, low-HuR expression was associated with an unfavorable response to EGFR-TKIs. Mechanistically, HuR affected the clinical outcomes of EGFR-TKI treatment of NSCLC by influencing Bim expression. The current study also found that lower HuR expression resulted in resistance to EGFR-TKIs by inhibiting apoptosis. In addition, xenograft tumor growth in nude mice induced by H1650 cells overexpressing HuR was completely suppressed by an EGFR inhibitor (gefitinib); however, complete tumor inhibition was not observed in the control (low HuR expression) group. These findings strongly supported the observations in the cell model and revealed that HuR-mediated Bim expression confers EGFR-TKI sensitivity.

The Bcl-2 family consists of anti-apoptotic and pro-apoptotic proteins regulating apoptosis (32-35). As a tumor suppressor, Bim is one of the most powerful $\mathrm{BH} 3$-only proteins and is able to engage all pro-survival proteins. Deregulating Bim expression at the genetic, transcriptional and post-translational levels may confer resistance to apoptosis $(10,36)$. In addition, Bim upregulation is associated with gefitinib-induced apoptosis in EGFR-mutant lung cancer cells (37). Therefore, Bim expression may correlate with the sensitivity to EGFR-TKIs (38). In addition to the contribution of Bim to the sensitivity to EGFR-TKIs, HuR expression may also confer such sensitivity in EGFR-mutant lung cancer cells.

HuR is a RNA-binding protein in the placenta lethal abnormal visual (embryonic lethal abnormal vision) family, and is located on chromosome 19p13.2 (27,39). HuR has been reported to be associated with numerous human carcinomas, including breast (40), liver $(41)$, pancreatic $(42)$, ovarian $(43,44)$ and colorectal cancer, as well as NSCLC $(45,46)$. Recently published studies indicated that elevated HuR expression is associated with aggressiveness and poor prognosis in patients with invasive breast carcinoma and lung carcinoma $(47,48)$. Furthermore, HuR also stabilizes mRNAs encoding crucial regulators of cellular proliferation, differentiation and stress response, such as cyclins (49), cyclooxygenase-2 $(50,51)$, p21 (52), HER2 (53) and Bcl-2 (54,55). However, the role of HuR in EGFR-TKI resistance in NSCLC and the associated mechanism have not been reported.

In the present study, specimens were collected from 81 NSCLC patients who received EGFR-TKI therapy to examine whether HuR and Bim expression levels were associated with the response to EGFR-TKIs and the patients' PFS. The study indicated that the HuR protein expression in tumor tissues was positively correlated with EGFR-TKI response in the patients with NSCLC. Furthermore, the expression of cytoplasmic Bim was closely correlated with HuR expression $(\mathrm{P}<0.01)$, but was not correlated with the sex, age and mutation type $(\mathrm{P}>0.05)$. In the EGFR-TKI-sensitive group, patients with 
high HuR tumor expression exhibited longer mPFS following EGFR-TKI therapy in comparison with those with low HuR expression (16.5 months vs. 9.7 months, respectively; $\mathrm{P}<0.01$ ). Similarly, the mPFS of patients with positive Bim expression was significantly higher than that of patients with negative Bim expression (12.8 months vs. 9.7 months, respectively; $\mathrm{P}<0.01$ ). Kaplan-Meier analysis also revealed that patients with low HuR and Bim expression levels exhibited a shorter PFS as compared with those with high HuR and Bim expression levels. In three lung cancer cell lines that harbor an EGFR mutation, RT-qPCR and western blotting demonstrated that HuR and Bim expression was significantly lower in the EGFR-TKI-resistant cell line H1650 when compared with the EGFR-TKI-sensitive cell lines HCC827 and PC9. Therefore, the present study suggests that $\mathrm{HuR}$ and Bim levels may be predictive of the treatment response and outcome of EGFR-TKI therapy in NSCLC patients harboring EGFR mutations. However, the collected cases all involved patients with lung adenocarcinoma, with the majority of patients presenting IV stage disease, which is a limitation of the current study. Therefore, further expansion of the corresponding cases and further subgroup analysis should be performed in future studies.

Knockdown of HuR expression was also conducted in the current study, which resulted in resistance to EGFR-TKIs in HCC 827 cells by decreasing apoptosis. In addition, the expression levels of HuR and Bim in HuR-knockdown HCC827 cells was lower compared with that in the control group. By contrast, overexpression of HuR restored the sensitivity to EGFR-TKIs in H1650 cells by increasing apoptosis. Accordingly, HuR and Bim expression levels in the HuR-transduced H1650 group were higher than those in the control group. High expression of HuR was associated with EGFR-TKI sensitivity through upregulation of Bim expression. These findings indicated that HuR serves functionally important roles in the sensitivity of cancer cells to EGFR-TKIs. Furthermore, resistance to EGFR-TKIs was observed when HuR was suppressed in cancer cells. To further validate the role of $\mathrm{HuR}$ in regulating EGFR-TKI resistance, this protein was overexpressed in a xenograft mouse model. In agreement with the in vitro data, HuR overexpression restored gefitinib sensitivity in the mouse model.

However, a limitation of the present study is that the results did not indicate the direct regulation of HuR on Bim. It was observed that low expression of HuR can lead to low expression of Bim and the change of cell apoptosis. Therefore, HuR may be able to affect apoptosis by regulating Bim expression In the follow-up experiments, further investigation of the correlation between $\mathrm{HuR}$ and other associated factors that can cause apoptosis will be performed. Further investigation is also required to identify the underlying molecular mechanisms. In addition, the correlation between HuR and Bim was only confirmed in one cell line; thus, subsequent studies should confirm this correlation in more cell lines, and further prove these results.

In conclusion, the present study suggested that decreased Bim expression, resulting from HuR downregulation, may confer primary resistance to EGFR-TKIs in EGFR-mutant lung cancer cells. Therefore, it is suggested that decreasing HuR expression in patients with NSCLC may predict primary resistance to EGFR-TKI treatment. The data also indicated that altered $\mathrm{HuR} / \mathrm{Bim}$ expression constitutes a novel mechanism of primary EGFR-TKI resistance in NSCLC, and provided a rationale for therapeutic strategies to reverse gefitinib resistance in NSCLC.

\section{Acknowledgements}

Not applicable.

\section{Funding}

This study was supported by the National Nature Science Foundation of China (grant nos. 81572875 and 81272619).

\section{Availability of data and materials}

The datasets used and/or analyzed during the current study are available from the corresponding author on reasonable request.

\section{Authors' contributions}

YY, HC, JW and BW made substantial contributions to the concept and design of the present study. YY and BW drafted the manuscript. All authors read and approved the final manuscript.

\section{Ethics approval and consent to participate}

The present study was approved by the Ethics Committee of the General Hospital (Jinan Command of the People's Liberation Army, Jinan, China). Written informed consent was obtained from all patients at the time of enrollment.

\section{Patient consent for publication}

Not applicable.

\section{Competing interests}

The authors declare that they have no competing interests.

\section{References}

1. Siegel RL, Miller KD and Jemal A: Cancer Statistics, 2015. CA Cancer J Clin 65: 5-29, 2015.

2. Naidoo J, Sima CS, Rodriguez K, Busby N, Nafa K, Ladanyi M, Riely GJ, Kris MG, Arcila ME and Yu HA: Epidermal growth factor receptor exon 20 insertions in advanced lung adenocarcinomas: Clinical outcomes and response to erlotinib. Cancer 121: 3212-3220, 2015.

3. Ettinger DS, Akerley W, Bepler G, Blum MG, Chang A, Cheney RT, Chirieac LR, D'Amico TA, Demmy TL, Ganti AK, et al: Non-small cell lung cancer. J Natl Compr Canc Netw 8: 740-801, 2010.

4. Paez JG, Jänne PA, Lee JC, Tracy S, Greulich H, Gabriel S, Harman P, Kaye FJ, Lindeman N, Boggon TJ, et al: EGFR mutations in lung cancer: Correlation with clinical response to gefitinib therapy. Science 304: 1497-1500, 2004.

5. Lynch TJ, Bell DW, Sordella R, Gurubhagavatula S, Okimoto RA, Brannigan BW, Harris PL, Haserlat SM, Supko JG, Haluska FG, et al: Activating mutations in the epidermal growth factor receptor underlying responsiveness of non-small-cell lung cancer to gefitinib. N Engl J Med 350: 2129-2139, 2004.

6. Mok TS, Wu YL, Thongprasert S, Yang CH, Chu DT, Saijo N, Sunpaweravong P, Han B, Margono B, Ichinose Y, et al: Gefitinib or carboplatin-paclitaxel in pulmonary adenocarcinoma. N Engl J Med 361: 947-957, 2009. 
7. Maemondo M, Inoue A, Kobayashi K, Sugawara S, Oizumi S, Isobe H, Gemma A, Harada M, Yoshizawa H, Kinoshita I, et al: Gefitinib or chemotherapy for non-small-cell lung cancer with mutated EGFR. N Engl J Med 362: 2380-2388, 2010.

8. Takeuchi S and Yano S: Clinical significance of epidermal growth factor receptor tyrosine kinase inhibitors: Sensitivity and resistance. Respir Investig 52: 348-356, 2014.

9. Jackman D, Pao W, Riely GJ, Engelman JA, Kris MG, Jänne PA, Lynch T, Johnson BE and Miller VA: Clinical definition of acquired resistance to epidermal growth factor receptor tyrosine kinase inhibitors in non-small-cell lung cancer. J Clin Oncol 28 : $357-360,2010$

10. O'Connor L, Strasser A, O'Reilly LA, Hausmann G, Adams JM, Cory S and Huang DC: Bim: A novel member of the Bcl-2 family that promotes apoptosis. EMBO J 17: 384-395, 1998.

11. Harada $\mathrm{H}$ and Grant $\mathrm{S}$ : Targeting the regulatory machinery of BIM for cancer therapy. Crit Rev Eukaryot Gene Expr 22: 117-129, 2012.

12. Bouillet P, Metcalf D, Huang DC, Tarlinton DM, Kay TW, Köntgen F, Adams JM and Strasser A: Proapoptotic Bcl-2 relative Bim required for certain apoptotic responses, leukocyte homeostasis, and to preclude autoimmunity. Science 286: 1735-1738, 1999.

13. Bouillet P, Purton JF, Godfrey DI, Zhang LC, Coultas L, Puthalakath H, Pellegrini M, Cory S, Adams JM and Strasser A $\mathrm{BH} 3$-only Bcl-2 family member Bim is required for apoptosis of autoreactive thymocytes. Nature 415: 922-926, 2002.

14. Gong YX, Somwar R, Politi K, Balak M, Chmielecki J, Jiang X and Pao W: Induction of BIM is essential for apoptosis triggered by EGFR kinase inhibitors in mutant EGFR-dependent lung adenocarcinomas. PLoS Med 4: e294, 2007.

15. Cardona AF, Rojas L, Wills B, Arrieta O, Carranza H, Vargas C Otero J, Corrales-Rodrigues L, Martin C, Reguart N, et al: BIM deletion polymorphisms in Hispanic patients with non-small cell lung cancer carriers of EGFR mutations. Oncotarget 7 : 68933-68942, 2016

16. Garofalo M, Romano G, Di Leva G, Nuovo G, Jeon YJ Ngankeu A, Sun J, Lovat F, Alder H, Condorelli G, et al: EGFR and MET receptor tyrosine kinase-altered microRNA expression induces tumorigenesis and gefitinib resistance in lung cancers. Nat Med 18: 74-82, 2012

17. Lee JY, Ku BM, Lim SH, Lee MY, Kim H, Kim M, Kim S, Jung HA, Sun JM, Ahn JS, et al: The BIM deletion polymorphism and its clinical implication in patients with EGFR-mutant non-small-cell lung cancer treated with EGFR tyrosine kinase inhibitors. J Thorac Oncol 10: 903-909, 2015.

18. Faber AC, Corcoran RB, Ebi H, Sequist LV, Waltman BA, Chung E, Incio J, Digumarthy SR, Pollack SF, Song Y, et al: BIM expression in treatment-naive cancers predicts responsiveness to kinase inhibitors. Cancer Discov 1: 352-365, 2011.

19. Filippova N, Yang X, Wang Y, Gillespie GY, Langford C, King PH, Wheeler C and Nabors LB: The RNA-binding protein $\mathrm{HuR}$ promotes glioma growth and treatment resistance. Mol Cancer Res 9: 648-659, 2011

20. Brennan CM and Steitz JA: HuR and mRNA stability. Cell Mol Life Sci 58: 266-277, 2001

21. Heinonen M, Fagerholm R, Aaltonen K, Kilpivaara O, Aittomäki K, Blomqvist C, Heikkilä P, Haglund C, Nevanlinna H and Ristimäki A: Prognostic role of HuR in hereditary breast cancer. Clin Cancer Res 13: 6959-6963, 2007.

22. Giammanco A, Blanc V, Montenegro G, Klos C, Xie Y, Kennedy S, Luo J, Chang SH, Hla T, Nalbantoglu I, et al: Intestinal epithelial HuR modulates distinct pathways of proliferation and apoptosis and attenuates small intestinal and colonic tumor development. Cancer Res 74: 5322-5335, 2014.

23. Erkinheimo TL, Lassus H, Sivula A, Sengupta S, Furneaux H, Hla T, Haglund C, Butzow R and Ristimäki A: Cytoplasmic HuR expression correlates with poor outcome and with cyclooxygenase 2 expression in serous ovarian carcinoma. Cancer Res 63 : 7591-7594, 2003.

24. Denkert C, Koch I, von Keyserlingk N, Noske A, Niesporek S, Dietel $\mathrm{M}$ and Weichert W: Expression of the ELAV-like protein HuR in human colon cancer: Association with tumor stage and cyclooxygenase-2. Mod Path 19: 1261-1269, 2006.

25. Costantino CL, Witkiewicz AK, Kuwano Y, Cozzitorto JA, Kennedy EP, Dasgupta A, Keen JC, Yeo CJ, Gorospe M and Brody JR: The role of HuR in gemcitabine efficacy in pancreatic cancer: HuR upregulates the expression of the gemcitabine metabolizing enzyme deoxycytidine kinase. Cancer Res 69: 4567-4572, 2009.
26. Beasley MB, Brambilla E and Travis WD: The 2004 World Health Organization classification of lung tumors. Semin Roentgenol 40: 90-97, 2005.

27. De K I, Mirhosseini M, Lau F, Thai V, Downing M, Quan H, Lesperance $\mathrm{M}$ and Yang J: Conversion of Karnofsky Performance Status (KPS) and Eastern Cooperative Oncology Group Performance Status (ECOG) to Palliative Performance Scale (PPS), and the interchangeability of PPS and KPS in prognostic tools. J Palliat Care 29: 163-169, 2013

28. Yu X, Zhan X, D'Costa J, Tanavde VM, Ye Z, Peng T, Malehorn MT, Yang X, Civin CI and Cheng L: Lentiviral vectors with two independent internal promoters transfer high-level expression of multiple transgenes to human hematopoietic stem-progenitor cells. Mol Ther 7: 827-838, 2003.

29. Livak KJ and Schmittgen TD: Analysis of relative gene expression data using real-time quantitative PCR and the $2^{-\Delta \Delta C T}$ method. Methods 25: 402-408, 2001.

30. Wang J, Li D, Wang B and Wu Y: Predictive and prognostic significance of cytoplasmic expression of ELAV-like protein HuR in invasive breast cancer treated with neoadjuvant chemotherapy. Breast Cancer Res Treat 141: 213-224, 2013.

31. Maimaiti Y, Dong L, Aili A, Maimaitiaili M, Huang T and Abudureyimu K: Bim may be a poor prognostic biomarker in breast cancer patients especially in those with luminal A tumors. Cancer Biomarkers 19: 411-418, 2017.

32. Czabotar PE, Lessene G, Strasser A and Adams JM: Control of apoptosis by the BCL-2 protein family: Implications for physiology and therapy. Nature Rev Mol Cell Biol 15: 49-63, 2014.

33. Green DR and Reed JC: Mitochondria and apoptosis. Science 281: 1309-1312, 1998

34. Gross A, McDonnell JM and Korsmeyer SJ: BCL-2 family members and the mitochondria in apoptosis. Genes Dev 13: 1899-1911, 1999.

35. Sarosiek KA and Letai A: Directly targeting the mitochondrial pathway of apoptosis for cancer therapy using $\mathrm{BH} 3$ mimetics-recent successes, current challenges and future promise. FEBS J 283: 3523-3533, 2016.

36. Wu DW, Chen CY, Chu CL and Lee H: Paxillin confers resistance to tyrosine kinase inhibitors in EGFR-mutant lung cancers via modulating BIM and Mcl-1 protein stability. Oncogene 35: 621-630, 2015.

37. Li H, Zhou S, Li X, Wang D, Wang Y, Zhou C and SchmidBindert G: Gefitinib-resistance is related to BIM expression in non-small cell lung cancer cell lines. Cancer Biother Radiopharm 28: 115-123, 2013

38. Costa C, Molina MA, Drozdowskyj A, Giménez-Capitán A, Bertran-Alamillo J, Karachaliou N, Gervias R, Massuit B, Wei J, Moran T, et al: The impact of EGFR T790M mutations and BIM mRNA expression on outcome in patients with EGFR-mutant NSCLC treated with erlotinib or chemotherapy in the randomized phase III EURTAC trial. Clin Cancer Res 20: 2001-2010, 2014.

39. Wang D, Wang M, Hu C, Shuang T, Zhou Y and Yan X: Expression of the ELAV-like protein HuR in the cytoplasm is associated with endometrial carcinoma progression. Tumor Biol 35: 11939-11947, 2014.

40. Wang J, Guo Y, Chu H, Guan Y, Bi J and Wang B: Multiple functions of the RNA-binding protein HuR in cancer progression, treatment responses and prognosis. Int J Mol Sci 14: 10015-10041, 2014.

41. Zhu H, Berkova Z, Mathur R, Sehgal L, Khashab T, Tao RH, Ao X, Feng L, Sabichi AL, Blechacz B, et al: HuR suppresses Fas expression and correlates with patient outcome in liver cancer. Mol Cancer Res 13: 809-818, 2015.

42. Romeo C, Weber MC, Zarei M, DeCicco D, Chand SN, Lobo AD, Winter JM, Sawicki JA, Sachs JN, Meisner-Kober N, et al: HuR contributes to TRAIL resistance by restricting death receptor 4 expression in pancreatic cancer cells. Mol Cancer Res 14: 599-611, 2016.

43. Prislei S, Martinelli E, Mariani M, Raspaglio G, Sieber S, Ferrandina G, Shahabi S, Scambia G and Ferlini C: MiR-200c and HuR in ovarian cancer. BMC Cancer 13: 72, 2013.

44. Sawicki JA, Huang YH, Brody JR, Getts RC, Rhodes K and Gerhart J: Abstract 3542: Inhibition of HuR effectively suppresses ovarian tumor growth in mice. Cancer Res 75 (15 Suppl), Abstract nr 3542, 2015.

45. Wang J, Wang B, Bi J and Zhang C: Cytoplasmic HuR expression correlates with angiogenesis, lymphangiogenesis, and poor outcome in lung cancer. Med Oncol 28: S577-S585, 2011. 
46. Wang J, Zhao W, Guo Y, Zhang B, Xie Q, Xiang D, Gao J, Wang $B$ and Chen Z: The expression of RNA-binding protein HuR in non-small cell lung cancer correlates with vascular endothelial growth factor-C expression and lymph node metastasis. Oncology 76: 420-429, 2009.

47. Vigouroux C, Casse JM, Battaglia-Hsu SF, Brochin L, Luc A, Paris C, Lacomme S, Gueant JL, Vignaud JM and Gauchotte G: Methyl(R217)HuR and MCM6 are inversely correlated and are prognostic markers in non small cell lung carcinoma. Lung Cancer 89: 189-196, 2015.

48. Giaginis C, Sampani A, Kotta-Loizou I, Giannopoulou I, Danas E, Politi E, Tsourouflis G, Kouraklis G, Patsouris E, Keramopoulos A, et al: Elevated hu-antigen receptor (HuR) expression is associated with tumor aggressiveness and poor prognosis but not with COX-2 expression in invasive breast carcinoma patients. Pathol Oncol Res 24: 631-640, 2018.

49. Wang W, Caldwell MC, Lin S, Furneaux H and Gorospe M: HuR regulates cyclin A and cyclin B1 mRNA stability during cell proliferation. EMBO J 19: 2340-2350, 2000.

50. Fernau NS, Fugmann D, Leyendecker M, Reimann K Grether-Beck S, Galban S, Ale-Agha N, Krutmann J and Klotz LO: Role of HuR and $\mathrm{p} 38^{\mathrm{MAPR}}$ in ultraviolet B-induced post-transcriptional regulation of COX-2 expression in the human keratinocyte cell line HaCaT. J Biol Chem 285: 3896-3904, 2010.
51. Serini S, Fasano E, Piccioni E, Monego G, Cittadini AR, Celleno L, Ranelletti FO and Calviello G: DHA induces apoptosis and differentiation in human melanoma cells in vitro: Involvement of HuR-mediated COX-2 mRNA stabilization and $\beta$-catenin nuclear translocation. Carcinogenesis 33: 164-173, 2012.

52. Wang W, Furneaux H, Cheng H, Caldwell MC, Hutter D, Liu Y, Holbrook N and Gorospe M: HuR regulates p21 mRNA stabilization by UV light. Mol Cell Biol 20: 760-769, 2000.

53. Hung CM, Huang WC, Pan HL, Chien PH, Lin CW, Chen LC, Chien YF, Lin CC, Leow KH, Chen WS, et al: Hepatitis B virus X upregulates HuR protein level to stabilize HER2 expression in hepatocellular carcinoma cells. Biomed Res Int 2014: 827415, 2014.

54. Ishimaru D, Ramalingam S, Sengupta TK, Bandyopadhyay S, Dellis S, Tholanikunnel BG, Fernandes DJ and Spicer EK: Regulation of Bcl-2 expression by HuR in HL60 leukemia cells and A431 carcinoma cells. Mol Cancer Res 7: 1354-1366, 2009.

55. Spicer EK, Ishimaru D, Ramalingam S, Tholanikunnel BG and Fernandes DJ: Role of HuR in the regulation of bcl-2 mRNA stability in human HL60 leukemia cells. FASEB J 22 (1 Suppl): 786.5, 2008. 